Artigo

\title{
Contribuições da Modelagem Matemática para o desenvolvimento de ações de motivação e engajamento no Ensino Médio
}

\author{
Contributions of Mathematical Modeling to the development of motivation and \\ engagement actions in High School
}

\section{Contribuciones del modelado matemático al desarrollo de acciones de motivación y compromiso en la escuela secundaria}

\author{
Neuber Silva Ferreira ${ }^{1}$ \\ [0000-0002-1588-4254] \\ Carlos Fernando Araújo Junior ${ }^{2}$ \\ [0000-0001-8188-161X]
}

\begin{abstract}
Resumo
Este texto discute a utilização de atividades de Modelagem Matemática e de tecnologias digitais móveis em uma proposta de ensino de Matemática para o Ensino Médio. $O$ objetivo da pesquisa foi analisar as atividades de Modelagem Matemática e discutir as contribuições destas atividades para o desenvolvimento de ações de motivação e engajamento dos alunos nas aulas de Matemática. A pesquisa tem características qualitativas, foi realizada no primeiro e segundo trimestre do letivo do ano de 2019, utilizou a metodologia de pesquisa Design Based Research e teve como público-alvo os alunos de duas turmas do primeiro ano do Ensino Médio de um Instituto Federal em Minas Gerais. A análise dos dados e a discussão dos resultados aconteceram tendo como referência as contribuições da Modelagem Matemática para a promoção e desenvolvimento de ações de motivação e engajamento. Os resultados mostraram que a utilização das atividades investigativas de Modelagem Matemática contribuiu para promover ações de motivação e engajamento e possibilitou que os alunos desenvolvessem habilidades para lidar com as informações, detectar variações, realizar previsões, documentar, argumentar e perceber que os modelos são gerados à luz da incerteza.
\end{abstract}

Palavras-chave: Modelagem Matemática. Proposta de ensino. Motivação e engajamento. Ensino Médio.

\begin{abstract}
This text discusses the use of Mathematical Modeling activities and mobile digital technologies in a proposal for teaching Mathematics for High School. The objective of the research was to analyze the activities of Mathematical Modeling and discuss the contributions of these activities to the development of actions of motivation and engagement of students in Mathematics classes. The research has qualitative characteristics, it was carried out in the first and second quarter of the academic year of 2019, used the Design Based Research research methodology and had as target audience the students of two classes of the first year of High School of a Federal Institute in Minas Gerais. The analysis of the data and the discussion of the results took place with reference to the contributions of Mathematical Modeling for the promotion and development of actions of motivation and engagement. The results showed that the use of investigative activities of Mathematical Modeling

${ }^{1}$ neuber.ferreira@ifmg.edu.br, Doutorando em Ensino de Ciências e Matemática, Professor do Instituto Federal de Educação, Ciência e Tecnologia de Minas Gerais, IFMG, Ouro Preto/Minas Gerais/Brasil.

2 carlos.araujo@cruzeirodosul.edu.br, Doutor em Física, Professor do Programa de Pós-Graduação em Ensino de Ciências e Matemática da Universidade Cruzeiro do Sul, UNICSUL, São Paulo/São Paulo/Brasil.
\end{abstract}


contributed to promote actions of motivation and engagement and enabled students to develop skills to deal with information, detect variations, make predictions, document, argue and realize that the models are generated light of uncertainty.

Keywords: Mathematical Modeling. Teaching proposal. Motivation and engagement. High school.

\section{Resumen}

Este texto analiza el uso de actividades de Modelado Matemático y tecnologías digitales móviles en una propuesta para la enseñanza de Matemáticas para el Bachillerato. El objetivo de la investigación fue analizar las actividades de Modelado Matemático y discutir los aportes de estas actividades al desarrollo de acciones de motivación y compromiso de los estudiantes en las clases de Matemáticas. La investigación tiene características cualitativas, se llevó a cabo en el primer y segundo trimestre del año académico de 2019, utilizó la metodología de Investigación Basada en Diseño y tuvo como público objetivo a los estudiantes de dos clases del primer año de Bachillerato de un Instituto Federal. Minas Gerais. El análisis de los datos y la discusión de los resultados se llevó a cabo con referencia a los aportes del Modelado Matemático para la promoción y desarrollo de acciones de motivación y compromiso. Los resultados mostraron que el uso de actividades investigativas de Modelado Matemático contribuyó a promover acciones de motivación y compromiso y permitió a los estudiantes desarrollar habilidades para manejar información, detectar variaciones, hacer predicciones, documentar, argumentar y darse cuenta de que los modelos se generan. luz de la incertidumbre.

Palabras claves: Modelado Matemático. Propuesta docente. Motivación y compromiso. Escuela secundaria.

\section{Introdução}

A baixa proficiência ${ }^{3}$ dos alunos em Matemática, sobretudo no Ensino Médio, tem sido amplamente discutida no Brasil. Um dos motivos é o resultado dos alunos nas avaliações internacionais, divulgado e debatido no Brasil e no mundo, que tem provocado preocupações em relação à educação escolar e também orientado diferentes ações para incrementar a formação dos estudantes, tanto em disciplinas específicas quanto na preparação para o trabalho e a cidadania.

Alguns países, sobretudo os que compõem a OCDE, têm intensificado os trabalhos na determinação de planos estratégicos para que a Educação Básica possa avançar em relação às novas demandas da sociedade atual. No Brasil, estas determinações estão presentes na Base Nacional Comum Curricular (BNCC) por meio da indicação do que os alunos devem saber (considerando a constituição de conhecimentos, habilidades, atitudes e valores) e, sobretudo, do que devem saber fazer (levando em conta a mobilização desses conhecimentos, habilidades, atitudes e valores para resolver demandas complexas da vida cotidiana, do pleno exercício da cidadania e do mundo do trabalho) (BRASIL, 2017, p.13).

Na BNCC, a área de Matemática e suas Tecnologias no Ensino Fundamental centra-se no desenvolvimento da compreensão de conceitos e procedimentos em seus diferentes campos, visando à resolução de situações-problema. No Ensino Médio, a BNCC propõe a ampliação e o aprofundamento das aprendizagens essenciais desenvolvidas no Ensino

\footnotetext{
${ }^{3}$ Para mais informações veja os dados sobre o PISA 2018 publicados pelo Instituto Nacional de Estudo e Pesquisas Educacionais Anísio Teixeira (INEP), disponível em: http://portal.inep.gov.br/artigo//asset_publisher/B4AQV9zFY7Bv/content/pisa-2018-revela-baixo-desempenho-escolar-em-leituramatematica-e-ciencias-no-brasil/21206.
} 
Fundamental e, em continuidade a essas aprendizagens, foca na construção de uma visão integrada da Matemática, ainda na perspectiva de sua aplicação à realidade.

Nas indicações do documento, os estudantes devem utilizar conceitos, procedimentos e estratégias não apenas para resolver problemas, mas também para formulá-los, descrever dados, selecionar modelos matemáticos e desenvolver o pensamento computacional, por meio da utilização de diferentes recursos da área. O documento salienta que quando a realidade é a referência, é preciso levar em conta as vivências cotidianas dos estudantes do Ensino Médio envolvidos, em diferentes graus, dados por suas condições socioeconômicas, pelos avanços tecnológicos, pelas exigências do mercado de trabalho, pela potencialidade das mídias sociais, entre outros (BRASIL, 2017).

Nesse cenário, a Modelagem Matemática, portanto, merece destaque por seu papel no desenvolvimento da capacidade dos estudantes de analisar, raciocinar, tomar decisões e participar dos debates construtivos sobre questões locais e globais. Nesse contexto, é que este artigo, que é parte de uma pesquisa de doutorado que investigou as contribuições de uma proposta de ensino que utilizou Modelagem Matemática, na perspectiva da Educação Matemática, e Tecnologias Digitais Móveis (smartphone), no modelo do Mobile Learning, como estratégia para o ensino de Matemática no Ensino Médio, busca oferecer alternativas.

O objetivo deste artigo é discutir as contribuições das atividades de Modelagem Matemática para o desenvolvimento de ações de motivação e engajamento dos alunos nas aulas de Matemática, pois, de acordo com alguns pesquisadores, a motivação e o engajamento são provavelmente fatores importantes para melhorar a aprendizagem, e têm sido foco de estudos na área da educação.

\section{Modelagem Matemática}

A Modelagem Matemática "busca investigar situações problemáticas do cotidiano e tem por objetivo a elaboração, a construção ou o estudo de um modelo matemático que descreva e/ou explique essas situações" (FERREIRA, 2013, p.38). De acordo com Blum e Ferri (2009), pode ser entendida como o processo de tradução entre o mundo real e a matemática em ambas as direções.

Suas raízes estão ancoradas na Matemática Aplicada, na qual o foco do processo de utilizar a Matemática para resolver problemas está no modelo a ser construído para caracterizar a situação. Assim, o objetivo é solucionar um problema de maneira adequada e simples.

Mas, apesar de suas raízes na Matemática Aplicada, a Modelagem Matemática faz parte do movimento da Educação Matemática há aproximadamente quarenta e cinco anos (MALHEIROS, 2012). No entanto, Silva (2018, p.18) pondera que "a transposição da Matemática Aplicada para a Educação Matemática não finalizou a modelagem nos seus usos e abordagens originais, mas deu início a novas abordagens, objetivos e contextos para sua utilização". Ou seja, matemáticos e profissionais de distintas áreas continuam construindo modelos que descrevem e/ou resolvem situações-problema. Porém, na Educação Matemática, a partir dessa transposição, os objetivos, a forma de abordagens e as discussões matemáticas passaram a diferir dos modeladores profissionais (BARBOSA, 2001).

No âmbito das salas de aula, diversas experiências de atividades de Modelagem Matemática têm sido conduzidas no Brasil e no exterior. Nessas experiências, o encaminhamento das atividades varia, muitas vezes, em função da necessidade de se atender 
às exigências impostas pelo contexto escolar e também de acordo com as concepções sobre o papel da modelagem no currículo.

Os procedimentos para a condução e compreensão da atividade de modelagem são, na maioria das vezes, apresentados em termos do processo de construção do modelo matemático, que se presta a descrever determinada problemática e sugerir soluções, atuando de forma a orientar as ações. Esse processo envolve um conjunto de ações desenvolvidas pelos estudantes - experimentação, seleção de variáveis, formulação de hipóteses, simplificações, resolução de problemas e validação do modelo vinculado ao contexto de uma situação não essencialmente matemática.

A maioria dos pesquisadores prefere não oferecer uma receita pronta para o professor trabalhar com a modelagem e sim indicar caminhos ou procedimentos. Kaiser (2014), por exemplo, sugere que um processo de modelagem deva ser feito com base no seguinte procedimento:

\begin{abstract}
Uma situação do mundo real é o ponto de partida do processo. Então a situação é idealizada, ou seja, simplificada ou estruturada para obter um modelo do mundo real. Então, esse modelo do mundo real é matematizado, ou seja, traduzido em um modelo matemático da situação original. Considerações matemáticas durante a construção do modelo matemático produzem resultados matemáticos que devem ser reinterpretados na situação real. A adequação dos resultados deve ser verificada, ou seja, validada. No caso de uma solução do problema ser insatisfatória, que acontece com bastante frequência na prática, esse processo deve ser iterado. (KAISER, 2014, p. 100).
\end{abstract}

Muitos autores baseiam suas atividades de Modelagem Matemática tendo como referência a representação do processo de modelagem em que o processo parte da situação real, segue para o modelo matemático e depois para os resultados matemáticos, e de volta à situação real (KAISER, 2014).

Ainda em relação à sala de aula, Silva (2018) afirma ser comum que os estudantes não tenham familiaridade com a modelagem como abordagem pedagógica, pois o desenvolvimento de atividades de modelagem nas aulas de Matemática não é algo corriqueiro, principalmente na Educação Básica. Ademais, conforme Blum (2015), a Modelagem Matemática é uma atividade de demanda cognitiva, que impõe dificuldades aos estudantes, uma vez que várias competências estão envolvidas, que podem ser competências não matemáticas, conhecimento matemático e extra matemático, noções conceituais, bem como conviç̧ões e atitudes adequadas. Nesse sentido, Silva $(2018$, p.27) pondera que "quando lidamos com alunos inexperientes em Modelagem Matemática, há a necessidade de introduzir a modelagem de forma gradual". E uma forma de fazer isso, de acordo com a autora, é por meio de momentos de familiarização com a Modelagem Matemática, conforme sugere o trabalho de Almeida e Dias (2004).

Almeida e Dias (2004) propõem a familiarização gradativa dos estudantes com a modelagem, no que chamam de "três momentos de familiarização". Em atividades do primeiro momento, o professor apresenta aos estudantes uma situação-problema, juntamente com outras informações necessárias. Nas atividades do segundo momento de familiarização, o professor pode sugerir uma situação-problema aos estudantes que, divididos em grupos, coletam mais informações para a investigação da situação. Atividades de 
modelagem do segundo momento se caracterizam por uma maior independência do estudante referente à definição de procedimentos para realizar a investigação. Durante atividades de modelagem do terceiro momento, os estudantes, em grupos, são responsáveis pela condução da atividade.

Segundo as autoras, a mediação feita pelo professor é mais intensa durante o primeiro e o segundo momentos, e fornece ao estudante confiança, independência e autoridade para estudar uma situação-problema, e buscar por meio da Matemática uma solução. Elas também afirmam que no decorrer dos diferentes momentos a independência e autonomia do estudante para o desenvolvimento da atividade vão aumentando, tornando-o responsável por todos os procedimentos no terceiro momento.

Em nossa proposta de ensino, ao trabalharmos com atividades de Modelagem Matemática com estudantes, optamos em seguir os momentos de familiarização sugeridos por Almeida e Dias (2004). Utilizamos os aspectos de uma atividade de Modelagem Matemática durante as aulas regulares, como uma forma de auxiliar a introdução de conceitos matemáticos ou o inverso, que é usar novos conceitos, métodos e resultados matemáticos para realizar atividades de modelagem.

\section{Motivação e engajamento}

Segundo Ali e Hassan (2018), o envolvimento dos alunos é um dos indicadores de seu desempenho acadêmico, sendo que os alunos ativamente envolvidos na escola têm melhor performance, atitudes e comportamentos positivos. De acordo com estes autores, o envolvimento dos alunos ocorre quando eles são desafiados a enfrentar vários obstáculos na tarefa ou atividade em que participam e demonstram motivação e engajamento em fazer o trabalho.

No entendimento de Camargo, Camargo e Souza (2019), a motivação na educação está relacionada com a curiosidade, o desejo de aprender, o propósito e a paixão que cada pessoa carrega dentro de si. Já o conceito de engajamento, segundo Bzuneck, Megliato e Rufini (2013), está de certa forma atrelado à motivação. Para estes autores, engajamento é "um constructo amplo que se refere à intensidade e qualidade dos comportamentos, emoções e recursos cognitivos com os quais uma pessoa se envolve ou que investe durante a realização de uma atividade" (p. 153). De acordo com Farias e Vaz (2019, p.5), "os conceitos de engajamento e motivação costumam ser tratados como se referissem a uma mesma coisa. Contudo, tratam-se de conceitos distintos". Segundo estes autores, pode ocorrer, por exemplo, que um estudante esteja motivado a ter uma boa atuação no geral, sem estar engajado em tarefas específicas da escola. Ademais, os autores explicam que:

a motivação se relaciona aos processos psicológicos que exercem influência sobre o comportamento dos estudantes em situações de aprendizagem. Ela está relacionada às razões ou motivos que levam determinada pessoa a agir de certa maneira. Já o engajamento se refere à relação que alguém - que está em contato com uma professora ou um professor, ou ainda, com outras pessoas bem definidas - estabelece com uma atividade bem específica; seja no tempo, seja nas demais circunstâncias ou características em que ela ocorre. (FARIAS; VAZ, 2019, p. 5). 
A motivação conduz as pessoas à ação. $E$ as pessoas são levadas a agir por diferentes fatores, desde a valorização de uma atividade até a coação externa (RAMOS, TRISTH; SALVI, 2011).

Pensando nos processos educacionais, Camargo, Camargo e Souza (2019, p. 598) afirmam que "a motivação é provavelmente o fator mais importante, a fim de melhorar a aprendizagem". Segundo estes autores, "no seu cerne, a motivação na educação é uma expressão inata de curiosidade; um desejo de aprender; uma manifestação de propósito e paixão que cada pessoa carrega dentro de si" (p.599).

Portanto, no entendimento destes e de outros pesquisadores (RAMOS, TRISTH; SALVI, 2011), a motivação do aluno para os estudos é considerada um fator muito importante para o êxito escolar, exercendo um papel fundamental na aprendizagem e no desempenho em sala de aula. Nesse sentido, Camargo, Camargo e Souza (2019) ressaltam que a motivação pode afetar o desempenho de habilidades, estratégias e comportamentos previamente aprendidos afetando, portanto, a aprendizagem. Sendo assim, ela pode influenciar o quê, quando e como aprendemos em todas as fases do nosso desenvolvimento.

Em relação ao engajamento, Skinner et al. (2008) distinguiram dois tipos básicos de engajamento, a saber, o comportamental e o emocional. O primeiro revela-se nos comportamentos de iniciar a ação, participar em classe, esforço, empenho, ataque, persistência, intensidade, atenção e concentração. A ausência de qualquer desses indicadores denota desengajamento comportamental. A dimensão comportamental envolve a participação e o envolvimento em uma atividade, especialmente no domínio de seu fazer.

$O$ engajamento emocional consiste num envolvimento afetivo na atividade de aprendizagem, ou seja, com a presença de emoções positivas, como entusiasmo, interesse, satisfação, prazer, orgulho, vitalidade e gosto. Seu oposto constitui-se na vivência de emoções negativas, como tédio, desinteresse, frustração e raiva, tristeza, ansiedade, vergonha e autorrecriminação. A dimensão emocional se relaciona às reações afetivas e emocionais diante da atividade e dos diferentes elementos que a constituem e dela participam.

Outro conceito de engajamento existente é o engajamento cognitivo, que se baseia no uso de estratégias de aprendizagem cognitivas, metacognitivas e de autorregulação. A dimensão cognitiva expressa investimento psicológico no sentido da compreensão do que se faz em determinada atividade, especialmente dos conceitos nela envolvidos. Expressa também ações de metacognição e de autorregulação da aprendizagem. Um estudante engajado cognitivamente vai além do mínimo solicitado, não faz a atividade por obrigação, é movido pelo desejo de aprender e desenvolve estratégias de controle da própria aprendizagem (FREDRICKS et al., 2004; FARIA, 2008). De acordo com os autores, esse é o engajamento típico para aprender.

No contexto educacional, existe o conceito de engajamento escolar. De acordo com Farias e Vaz (2019, p. 3), "engajamento escolar - ou simplesmente engajamento - se refere à relação que o estudante estabelece com as atividades escolares que lhes são propostas. Essa relação é influenciada pela interação dos estudantes com o contexto". Em síntese, engajamento escolar significa o envolvimento ativo do aluno em uma tarefa ou atividade de aprendizagem, em classe ou em outro ambiente.

Como na proposta de ensino, nosso objetivo é a aprendizagem da Matemática, e a motivação e o engajamento são fatores que contribuem para a aprendizagem. Entendemos que a Modelagem Matemática pode ser um agente motivador, de engajamento e contribuir 
para que os alunos se envolvam ativamente nos processos de ensino e aprendizagem da Matemática no Ensino Médio.

\section{Metodologia}

A pesquisa foi orientada metodologicamente, tendo como referência a Design-Based Research (DBR $)^{4}$, pois visou propiciar a integração entre a pesquisa e o desenvolvimento de intervenções educativas em contextos reais de aprendizagem. A escolha por esta metodologia aconteceu em função de suas características, que estão relacionadas com a fundamentação na teoria e na prática, na análise da literatura e de casos, em métodos qualitativos, além de ser uma metodologia interativa, iterativa e flexível (PLOMP; NIEVEEN, 2013).

Nesta investigação buscamos promover a melhoria das práticas educativas ao analisar como um ambiente de aprendizagem que utiliza a Modelagem Matemática, que é uma tendência educacional já consolidadas na literatura, pode contribuir para os processos de ensino e de aprendizagem da Matemática no Ensino Médio. Sendo assim, implementar, analisar e avaliar este ambiente se insere numa pesquisa na metodologia DBR.

Entendemos também que essas características são importantes para a investigação por estarem relacionadas com o ensino e aprendizagem, no qual é necessária observação contínua de aspectos qualitativos associados à repetição e avaliação de processos. Ademais, conforme afirmam Anderson e Shattuck (2012, apud Nunes, 2019), a metodologia DBR foi projetada por e para educadores com o objetivo de aumentar o impacto, a transferência e a tradução da pesquisa em educação para melhorar a prática. Isto é o que se pretende com esta investigação, pesquisar para aprimorar a experiência relacionada à aprendizagem de Matemática por meio de atividades de modelagem matemática.

A pesquisa foi realizada nos dois primeiros trimestres do ano letivo de $2019 \mathrm{em}$ um Instituto Federal de Educação Tecnológica no estado de Minas Gerais (IFMG). O professor pesquisador faz parte do corpo docente da instituição e buscou com sua pesquisa contribuir para melhorar a proficiência dos alunos em Matemática. Os dados foram coletados durante as aulas e nos momentos de interação virtual com os dispositivos móveis, em duas turmas de 10 ano do curso Técnico Integrado em Mineração. Os participantes da pesquisa foram os 80 alunos das duas turmas, o professor e o pesquisador.

Os instrumentos de coleta de dados utilizados foram: caderno de campo; gravações em áudio e vídeo das apresentações dos trabalhos; questionário online; trabalhos desenvolvidos pelos alunos nos ambientes de aprendizagem, trabalhos entregues durante as aulas, notas de aula do professor regente e todas as informações compartilhadas pelos alunos nos seus dispositivos móveis. A utilização de todos esses instrumentos de coleta de dados se justifica pela metodologia de pesquisa adotada.

\section{Descrição da proposta de ensino}

No planejamento anual da escola, o ano letivo é dividido em três etapas. Resolvemos que em cada etapa aplicaríamos a proposta de ensino, entendendo como um ciclo iterativo da proposta DBR. Entretanto, por motivos relacionados com o projeto de pesquisa aprovado

\footnotetext{
${ }^{4}$ Design Based Research ou Pesquisa baseada em Design faz referência ao conjunto de abordagens que assumem como compromisso "aliar pesquisa e desenvolvimento de intervenções pedagógicas em contextos reais de aprendizagem, com o objetivo tanto de promover a melhoria das práticas educativas quanto de produzir conhecimentos sobre o processo de ensino-aprendizagem." (RAMOS, 2010, p. 20).
} 
pelo Comitê de Ética em Pesquisa (CEP), no qual estava estipulado o período de recolha dos dados, iremos descrever e utilizar os dados coletados nas duas primeiras etapas. Sendo importante destacar que, em nosso entendimento, esse procedimento não prejudicou a análise e as conclusões da pesquisa, pois ao utilizarmos os dados das duas primeiras etapas tivemos a oportunidade de repetir as estratégias, aperfeiçoá-las e reaplicá-las seguindo as sugestões dos participantes, conforme a metodologia DBR.

Na primeira etapa, os conteúdos selecionados foram: noções de conjuntos, conjuntos numéricos, funções e função afim. Na proposta de ensino, eles foram abordados por meio das estratégias de ensino, conforme orientações dos teóricos e dos trabalhos estudados. Buscouse, inicialmente, trabalhar com a abordagem tradicional (usada pelo professor) e inserir de forma gradativa as estratégias com o uso da Modelagem Matemática e dos dispositivos móveis, para que os alunos pudessem se familiarizar com a abordagem proposta. Foi desenvolvida a atividade de modelagem - Números racionais, cores e música - baseada em (Rodrigues, 2008), planejada devido às dificuldades dos alunos em relação ao entendimento dos números racionais e irracionais. Para o conceito de função, usou-se a atividade de modelagem - o problema da conta de água do condomínio - de acordo com (Vidigal, 2013) e, por fim, para o conceito de função afim foi realizada a atividade de modelagem - Como é feito o cálculo das corridas de táxi e de aplicativos de mobilidade. Para estas atividades foram utilizados os aplicativos Socrative Student e Teacher, Geogebra, Calculadora Musicalcolorida, WhatsApp.

Na segunda etapa, os conteúdos foram: funções quadrática, exponencial, logarítmica e modular. Na proposta de ensino, esses conteúdos também foram abordados utilizando as estratégias de ensino, conforme orientações dos teóricos e dos trabalhos estudados. Foram realizadas as atividades de modelagem - Parábolas na arquitetura - para o entendimento sobre gráficos e aplicações da função quadrática, e - Modelagem na Mineração - para desenvolver competências e habilidades essenciais da Matemática. Nestas atividades foram utilizados os aplicativos Socrative Student e Teacher, Geogebra, WhatsApp e YouTube.

Conforme já salientamos, entendemos que as atividades de modelagem deveriam ser abordadas, conforme orientações de Almeida e Dias (2008), ou seja, de forma gradativa com os alunos. Foi nesse contexto que as atividades foram desenvolvidas, sendo introduzidas paulatinamente, possibilitando momentos de familiarização durante as aulas.

Nesse texto, não iremos apresentar e discutir todas as atividades de Modelagem Matemática da proposta de ensino realizadas e analisadas nas etapas letivas.

\section{Análise das contribuições para o desenvolvimento de ações de motivação e engajamento dos alunos}

A atividade que apresentamos e discutimos é a atividade Modelagem na Mineração. Esta atividade foi realizada nas duas turmas do primeiro ano do curso técnico integrado de Mineração. Além dos momentos presenciais, aconteceram também momentos de aprendizado com mobilidade, por meio da utilização dos smartphones e seus aplicativos, que possibilitaram coleta de informações, fomentaram discussões, compartilhamento de resultados de investigações, exposição e reflexão dos resultados.

Em ambas as turmas os procedimentos foram similares. No início da abordagem, os alunos foram informados sobre a atividade e quais os objetivos de sua aplicação. Em seguida, foi solicitado que se agrupassem para que as orientações fossem distribuídas. Houve uma 
breve explicação sobre o que era esperado dos alunos em relação à atividade. A atividade se iniciou e durante sua realização os professores participaram como mediadores, auxiliando os alunos em relação ao entendimento do problema e os estimulando a refletirem sobre o que deveriam investigar.

A atividade Modelagem na mineração, baseada no trabalho de Ferreira (2013), teve como objetivo trazer para o contexto educacional uma temática atual, relacionada com o quotidiano dos alunos, pois eles moravam em uma região mineradora. Também foi desenvolvida pela possibilidade de abordar situações-problema que pudessem aproximar experiências vividas pelos alunos em seu curso técnico, com a matemática escolar e com questões de relevância para sociedade em que estavam inseridos.

Pensando em ações de motivação, conforme Camargo, Camargo e Souza (2019), como uma força interior que estimula, dirige, mobiliza a pessoa para uma ação com entusiasmo, entendemos que a atividade de Modelagem proposta poderia contribuir para estimular, direcionar e mobilizar os estudantes para a ação de investigar, informar e estudar. O que de fato aconteceu, pois, o envolvimento dos alunos e a importância dada por eles às atividades puderam ser percebidos nos dados obtidos durante a pesquisa.

Reunidos em grupos, os estudantes foram convidados a investigar informações e problemas relacionados à mineração. Não foram definidos quais problemas, sendo assim, eles poderiam pesquisar questões econômicas, sociais, ambientais, de sustentabilidades, inovação, os impactos das mineradoras na região e/ou os desafios a serem superados em função dos desastres ocorridos.

Para a realização dessa atividade foi apresentada aos alunos uma reportagem do programa Fantástico intitulada Transformação do minério em ferro e em aço ${ }^{5}$ exibida no dia 7 de julho de 2019 e disponibilizada no dia 8 de julho de 2019. A reportagem explicou as etapas percorridas no processo, desde a extração do minério de ferro da mina até sua transformação em aço em uma siderúrgica, discutiu também a questão das barragens de rejeito e os impactos provocados pelo rompimento das barragens de Fundão, em Mariana/MG, e do Córrego do Feijão, em Brumadinho/MG.

A apresentação dessa reportagem foi uma estratégia motivacional. Buscou-se trazer para a sala de aula o debate que estava ocorrendo na comunidade e inserir os alunos nesse debate, bem como promover ações de engajamento dos alunos na busca por solucionar problemas relevantes para o seu contexto educacional. Segundo Camargo, Camargo e Souza (2019, p.599), "alunos motivados a aprender estão aptos a se engajar em atividades que acreditam que os ajudarão a aprender, como acompanhar cuidadosamente a instrução, organizar mentalmente e ensaiar o material a ser aprendido".

Vertuan (2007, p. 131) argumenta que o desenvolvimento de atividades de Modelagem Matemática coloca os estudantes "em um contexto de aprendizagem em que a discussão de situações-problema, a participação ativa e o uso de diferentes registros se fazem essenciais" e complementa que estas atividades podem proporcionar aos estudantes motivação e um melhor entendimento da aplicabilidade da Matemática.

Posteriormente a apresentação da reportagem, foi pedido aos alunos que se dividissem em grupos e conversassem sobre qual seria o assunto investigado dentro da temática. Na turma D2 foram formados cinco grupos de trabalho e na turma D3 seis grupos. Após algum tempo, os grupos apresentaram seus temas, que estão descritos no quadro 1.

\footnotetext{
${ }^{5}$ Disponível em https://youtu.be/iNas3yjGajl
} 
Quadro 1 - Temas do trabalho de Modelagem Matemática na Mineração

\begin{tabular}{|l|l|}
\hline TURMA D2 & TURMA D3 \\
\hline Grupo 1: Impacto ambiental - Desmatamento & $\begin{array}{l}\text { Grupo 1: Área de impacto gerado pelo rompimento } \\
\text { das barragens } \\
\text { Grupo 2: Impacto dos rejeitos nos rios }\end{array}$ \\
$\begin{array}{l}\text { Grupo 2: Vida útil das barragens } \\
\text { Grupo 3: Impacto econômico nos trabalhadores e na } \\
\text { cidade }\end{array}$ & $\begin{array}{l}\text { Grupo 3: Uso de água no beneficiamento do minério } \\
\text { Grupo 4: Rejeito a seco }\end{array}$ \\
$\begin{array}{l}\text { Grupo 4: Impactos Ambientais da barragem de } \\
\text { Brumadinho } \\
\text { Grupo 5: História das barragens }\end{array}$ \\
& Grupo 6: Barragem de Brumadinho Indenizações \\
\hline
\end{tabular}

Fonte: Banco de dados dos pesquisadores

O processo de escolha do tema na atividade de modelagem já possibilitou desenvolver ações de motivação. Nos dados obtidos nos relatórios das atividades, os diversos temas escolhidos refletem suas motivações em realizar o estudo e os ensejos que os moveram na investigação. Cada grupo explicou em suas justificativas o motivo da escolha. Para exemplificar, apresentamos a justificativa retirada do relatório de pesquisa do grupo 1 da turma D3. Esse grupo escolheu investigar a área de impacto do rompimento de barragens e, de acordo com os componentes, o que os motivou na investigação foi o descaso das empresas ao lidar com a vida humana, e a grande quantidade de pessoas que perderam suas vidas em um acidente recente.

Escolhemos este tema, pois achamos necessário o estudo do mesmo, a partir do momento em que podemos perceber o descaso das empresas privadas ao lidar com a vida humana e a falta de informação que lhes é oferecida. Portanto, a análise dos danos causados por um possivel rompimento de uma barragem é importantíssimo para conscientizar as pessoas dos riscos existentes e até mesmo alertar a população. (GRUPO 1, D3).

Observamos que os temas investigados e as informações apresentadas pelos grupos são fatores que influenciaram a motivação dos alunos, pois trazem significado para o processo de aprendizagem. Conforme afirmam Oliveira e Alves (2005, p. 603), "o significado que o conteúdo e a disciplina têm para o aluno, que varia de acordo com as metas e objetivos de cada pessoa, caso o aluno não perceba utilidade, o interesse tende a diminuir. Colocar problemas, despertar a curiosidade dos alunos, é essencial".

Durante a realização da atividade, os alunos foram orientados a utilizar seus smartphones para se reunirem e conversarem em seus grupos. Para que os professores pudessem acompanhar e orientar os trabalhos foi criado um arquivo com a ferramenta Google Docs para cada grupo. Nesse arquivo, os grupos construíram um texto coletivo com as informações pesquisadas, no qual deveria constar: uma introdução na qual deveriam responder: o porquê de pesquisar o tema, qual problema seria investigado e o que queriam responder sobre o problema; os dados e informações investigadas; matematização inicial do problema; modelo matemático e conclusões. Durante a construção do texto, os professores mediaram e orientaram os alunos em relação ao uso correto das informações obtidas e sobre a necessidade de citar a fonte e as referências. É importante salientar que nessa etapa da atividade de modelagem, o conteúdo científico estava contextualizado com as experiências que os alunos já vivenciaram, e o uso desse conteúdo levantou elementos que proporcionaram aumentar esse interesse. 
Na construção do texto sobre a temática investigada, percebemos contribuições em relação ao desenvolvimento de ações de engajamento escolar. Segundo Farias e Vaz (2019), atividades escolares de investigação têm o potencial de estimular o uso de estratégias de raciocínio e de aprendizagem, de favorecer a compreensão funcional de conceitos e de promover a colaboração e o engajamento dos estudantes.

Após concluírem a etapa de investigação e construção do texto, os alunos, com o auxílio dos professores, prepararam as apresentações dos resultados do trabalho e compartilharam com eles para que pudessem opinar, dar sugestões e ou fazer críticas. As explanações aconteceram em duas aulas, nas quais os grupos debateram sobre as investigações realizadas (figura 1).

Figura 1 - Apresentação dos grupos na atividade de modelagem

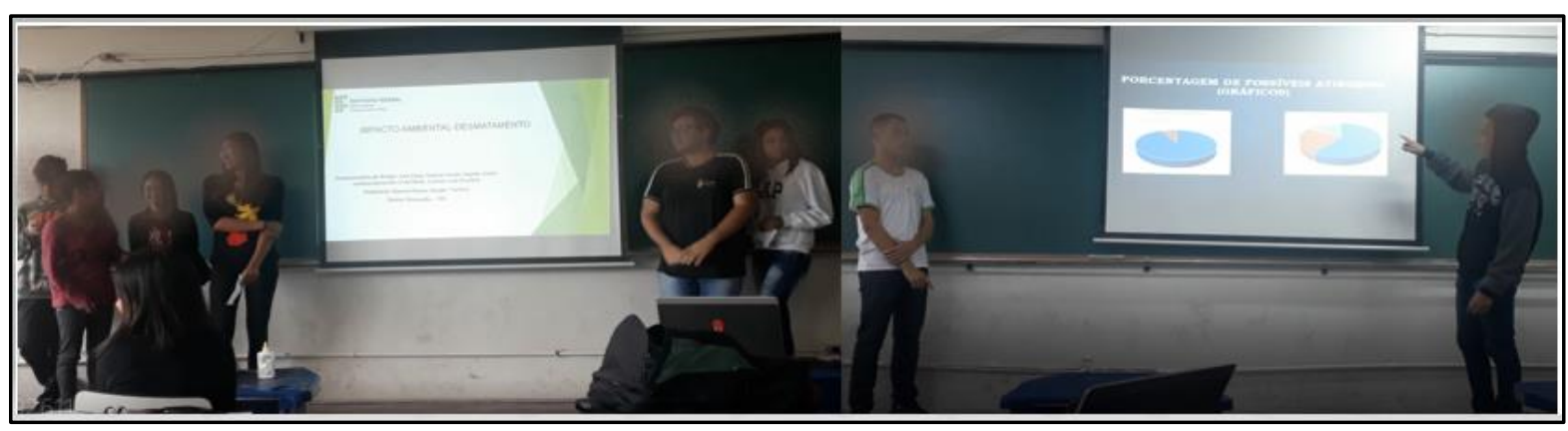

Fonte: Banco de dados do professor pesquisador

Durante as apresentações, foi possível observar contribuições no desenvolvimento de ações de engajamento no comportamento dos alunos, tais como, nas falas, nas informações apresentadas e nos modelos construídos para resolver as situações investigadas. Nas explicações dos modelos, os estudantes deram indícios de que estavam cognitivamente engajados ao recorrerem a conceitos matemáticos. De fato, o esforço dos alunos em grupo os fez atingir níveis um pouco mais elevados de compreensão sobre a situação-problema discutida, o que sugere ter havido engajamento cognitivo dos estudantes na atividade.

Figura 2 - Imagem da barragem Sul Superior em Barão de Cocais

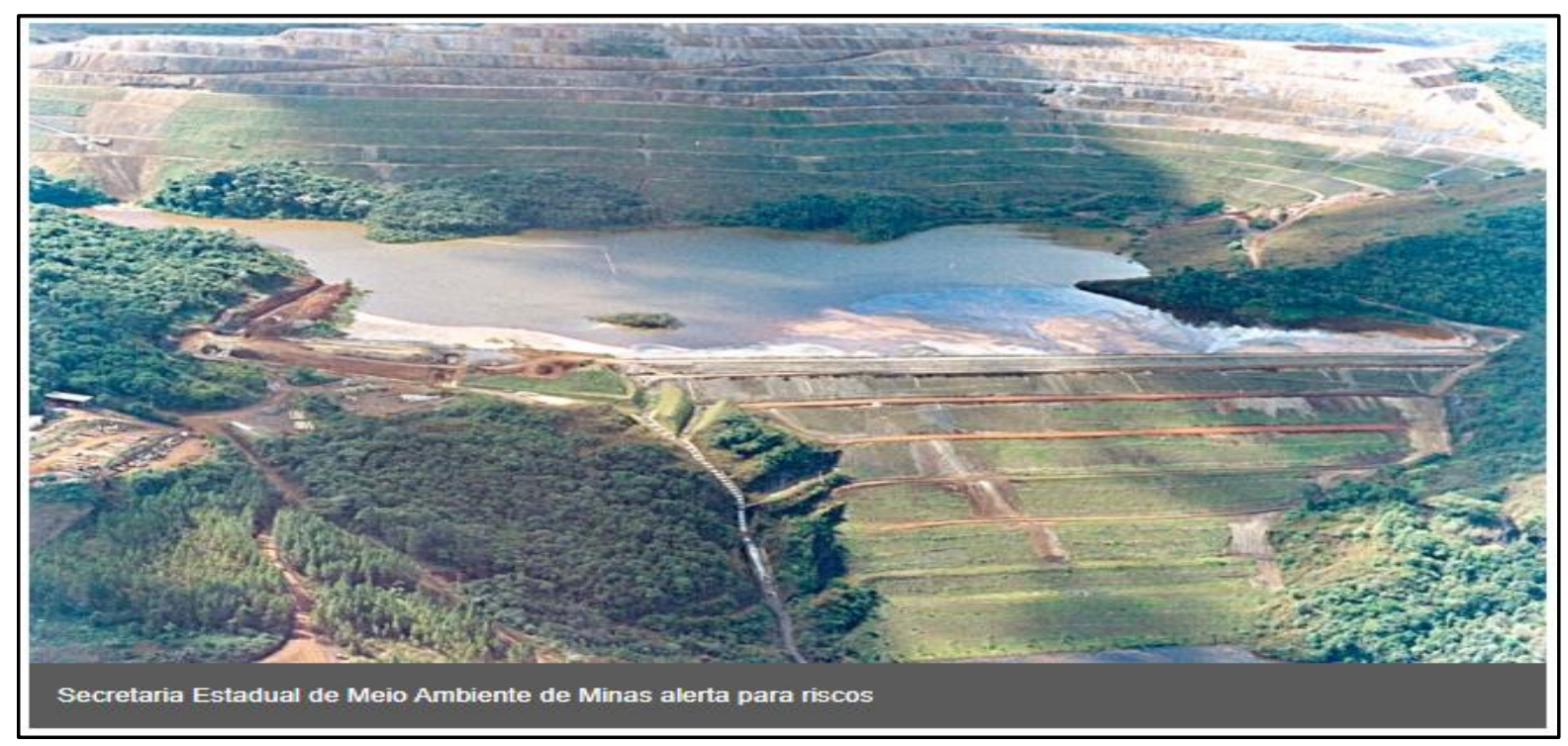

Fonte: Jornal Hoje em Dia, 15/04/2019 
Para exemplificarmos, vamos mostrar e discutir a apresentação do trabalho desenvolvido pelos os alunos do grupo 1 da turma D3. Esse grupo escolheu investigar os impactos gerados pelo rompimento das barragens das empresas mineradoras. A Barragem Sul Superior na mina de Gongo Soco, na cidade de Barão de Cocais, MG foi a escolhida para a simulação dos danos (figura 2). Na ocasião da pesquisa, essa barragem tinha um alto risco de rompimento, segundo dados da ANM - Agência Nacional de Mineração.

$\mathrm{Na}$ apresentação da investigação realizada, os alunos explicaram que se interessaram em simular os danos que poderiam ser provocados caso ocorresse o rompimento da barragem na cidade de Barão de Cocais. Assim, eles decidiram quantificar esses danos. Antes de quantificá-los, apresentaram informações sobre os tipos de barragens existentes, também abordaram as questões relacionadas às leis vigentes para estas estruturas e sobre as barragens existentes na região e a população atingida. Apresentaram suas considerações sobre os atingidos, com a finalidade de estimar a quantidade de possíveis pessoas e residências atingidas (figura 3 ).

Figura 3 - Slide da apresentação - Atingidos

\section{SOBRE OS POSSÍVEIS ATINGIDOS}

- Barão de Cocais terá o maior número de atingidos (26,88 mil indiretamente).

- Sabemos que o total de atingidos DIRETAMENTE, ou seja, que terão suas casas levadas será de mais de 10 mil habitantes, SUPONDO que em cada casa que será atingida viva 3 pessoas, daria ao todo cerca de 3,33 mil residências.

- Vamos supor também que o (até então) desastre hipotético não decorra a nenhuma morte, ou seja, que com todo o treinamento e preparação feita pela Vale haja um total de 0 vítimas fatais, logo levando em consideração somente as construções.

Fonte: Banco de dados dos pesquisadores

Após explicarem os cálculos realizados na estimativa, os alunos provocaram seus colegas para que respondessem qual era o entendimento deles em relação ao que seria um dano e consequentemente as dificuldades de quantificá-los.

Essa provocação teve o objetivo de motivá-los em relação ao problema apresentado, buscando maior envolvimento dos mesmos. Após algumas considerações da turma e ponderações do grupo, foram exibidos quais seriam os danos tangíveis e intangíveis (figura 4).

Nesse caso, a motivação tem uma relação recíproca com a aprendizagem e o desempenho; isto é, a motivação influencia a aprendizagem e o desempenho, e o que os alunos fazem e aprendem influencia sua motivação. Quando os alunos atingem as metas de aprendizado, a realização das metas transmite a eles que possuem as capacidades necessárias para o aprendizado. Essas crenças os motivam a estabelecer novos objetivos desafiadores. Os alunos que são motivados a aprender frequentemente descobrem que, quando o fazem, estão intrinsecamente motivados a continuar seu aprendizado (CAMARGO; CAMARGO; SOUZA, 2019 p. 604). 
Figura 4 - Slide da apresentação - danos considerados

\begin{tabular}{|c|c|c|c|c|}
\hline \multirow{2}{*}{ SETOR } & \multicolumn{2}{|c|}{ DANOS TANGIVEIS } & \multicolumn{2}{|c|}{ DANOS INTANGIVEIS } \\
\hline & Diretos & Indiretos & Diretos & Indiretos \\
\hline Habitacional & $\begin{array}{l}\text { - Danos físicos à } \\
\text { construçao; } \\
\text { - Conteúdo. }\end{array}$ & $\begin{array}{l}\text { - Custos de limpeza; } \\
\text {-Alojamento; } \\
\text { - Medicamentos. }\end{array}$ & $\begin{array}{l}\text { - Ferimentos e perdas de } \\
\text { vidas humanas; } \\
\text { - Doenças pelo contato } \\
\text { com a água; } \\
\text { - Perda de objetos de } \\
\text { valor sentimental; } \\
\text { - Perda de animais de } \\
\text { estimaçăo. }\end{array}$ & $\begin{array}{l}\text { - Estados psicológicos } \\
\text { de estresse e ansiedade; } \\
\text { - Danos de longo prazo à } \\
\text { saúde. }\end{array}$ \\
\hline $\begin{array}{l}\text { Comércio e } \\
\text { Serviços }\end{array}$ & $\begin{array}{c}\text { - Danos físicos à } \\
\text { construção: } \\
\text { - Conteúdo; } \\
\text { - Mobiliário, estoques, } \\
\text { mercadorias em } \\
\text { exposiçāo, etc. }\end{array}$ & $\begin{array}{l}\text { - Custos de limpeza; } \\
\text { - Lucros cessantes; } \\
\text { - Desemprego; } \\
\text { - Perda de base de } \\
\text { dados; } \\
\text { - Perda de renda. }\end{array}$ & $\begin{array}{l}\text { - Ferimentos e perdas de } \\
\text { vidas humanas; } \\
\text { - Doenças pelo contato } \\
\text { com a água. }\end{array}$ & $\begin{array}{c}\text { - Estados psicológicos } \\
\text { de estresse e ansiedade; } \\
\text { - Danos de longo prazo à } \\
\text { saúde; } \\
\text { - Inconvenientes de } \\
\text { interrupção de serviços; } \\
\text { - Falta de motivaçăo } \\
\text { para o trabalho. }\end{array}$ \\
\hline
\end{tabular}

Fonte: Banco de dados dos pesquisadores

Com a explicação dada sobre os danos, os alunos dos grupos definiram que seriam considerados para o modelo do trabalho apenas os danos tangíveis diretos e mostraram uma tabela que classificava o conteúdo das residências de acordo com a classe social (figura 5). A tabela motivou um debate interessante sobre a quantidade de bens e a questão das classes de renda.

Figura 5 - Slide da apresentação - conteúdo das residências

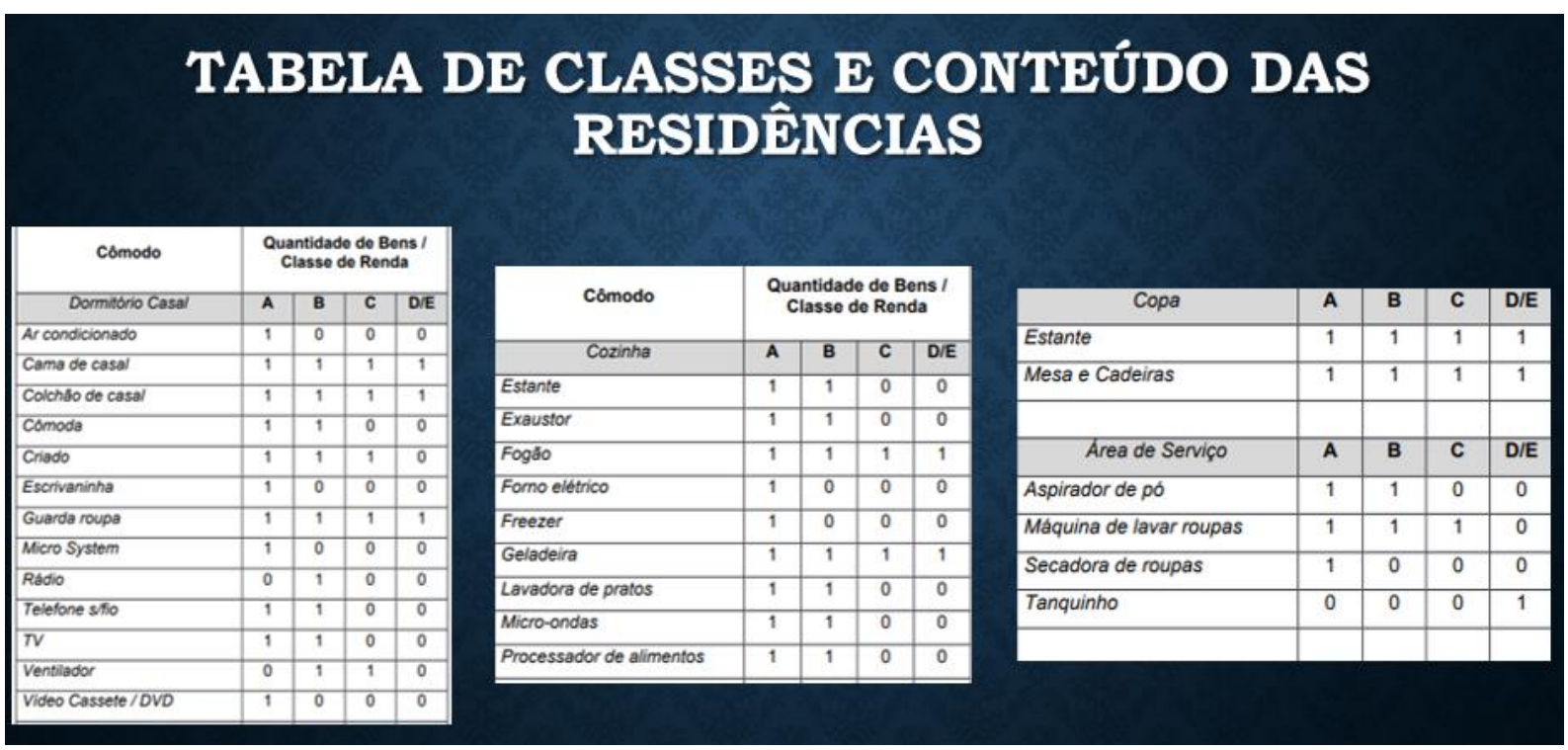

Fonte: Banco de dados dos pesquisadores

Com o debate ainda acontecendo, o grupo mostrou outra tabela (figura 6) com o preço de cada conteúdo das residências, indicando que existe também diferença nos valores dos bens conforme a classe de renda e explicou que esses valores foram necessários para fazer a estimativa do valor do conteúdo das residências. 
Figura 6 - Slide da apresentação - tabela de preços - conteúdos

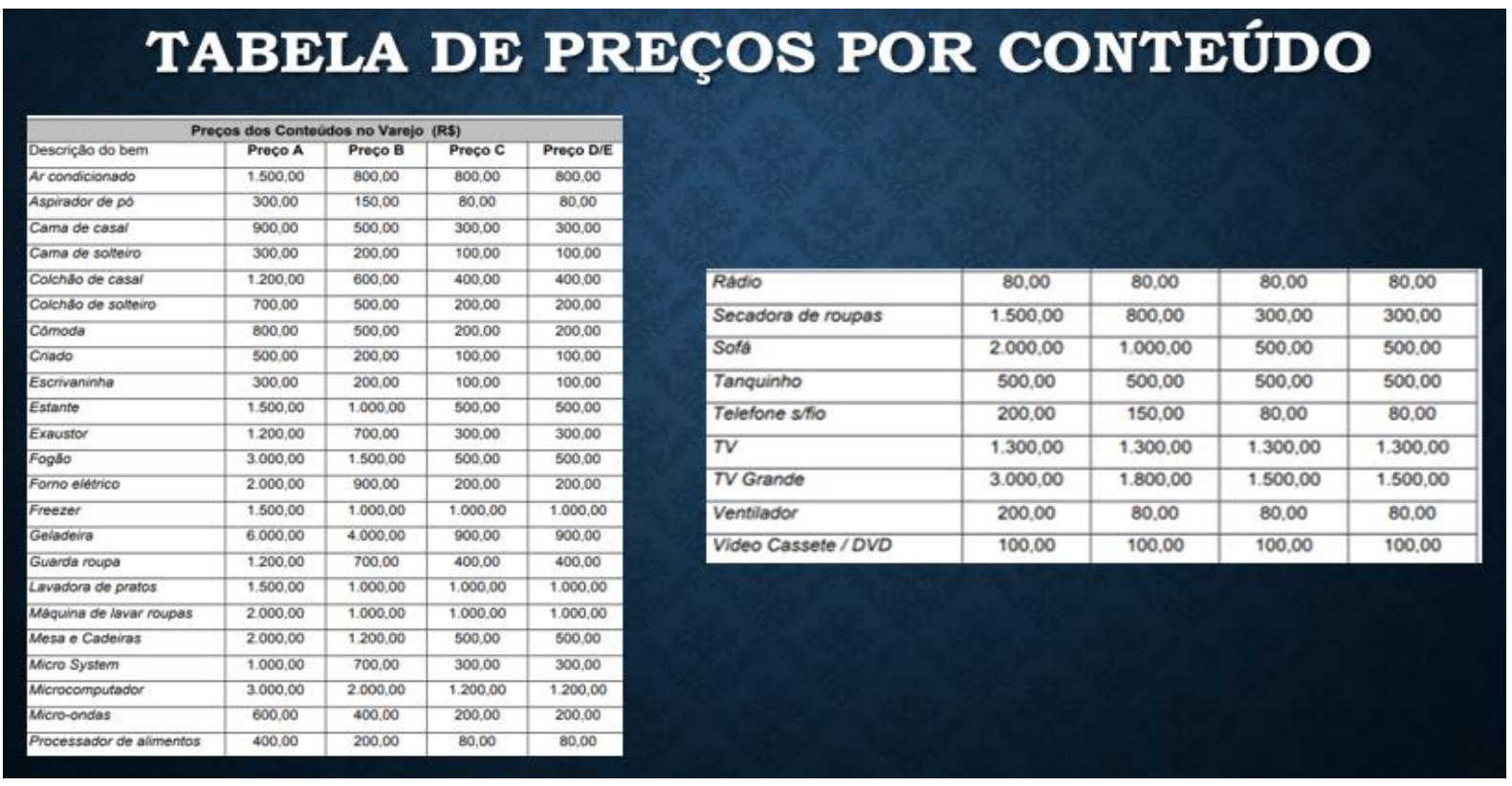

Fonte: Banco de dados dos pesquisadores

A partir dos dados apresentados nas duas tabelas, os alunos relataram que os utilizaram para calcular, ou seja, estimar o valor total dos conteúdos de uma residência do tipo C. Em seguida, levando em consideração a quantidade de residências anteriormente estimada por eles, calcularam o valor que a mineradora deveria pagar pelos danos de conteúdo (figura 7).

Figura 7 - Slide da apresentação - Valor total de conteúdo

\section{TOTAL DO CONTEÚDO DE UMA CASA DE CLASSE C}

- Ao somar todas as quantias e quantidades obtemos uma valor total de $\mathrm{R} \$ 8,36$ mil de conteúdo por residência. Levando em consideração a nossa aproximação de 3,33 mil residências atingidas o total que a mineradora teria que pagar pelos conteúdos seria de $\mathrm{R} \$ 27.838 .800$ ( vinte e sete milhões, oitocentos e trinta e oito mil e oitocentos reais).

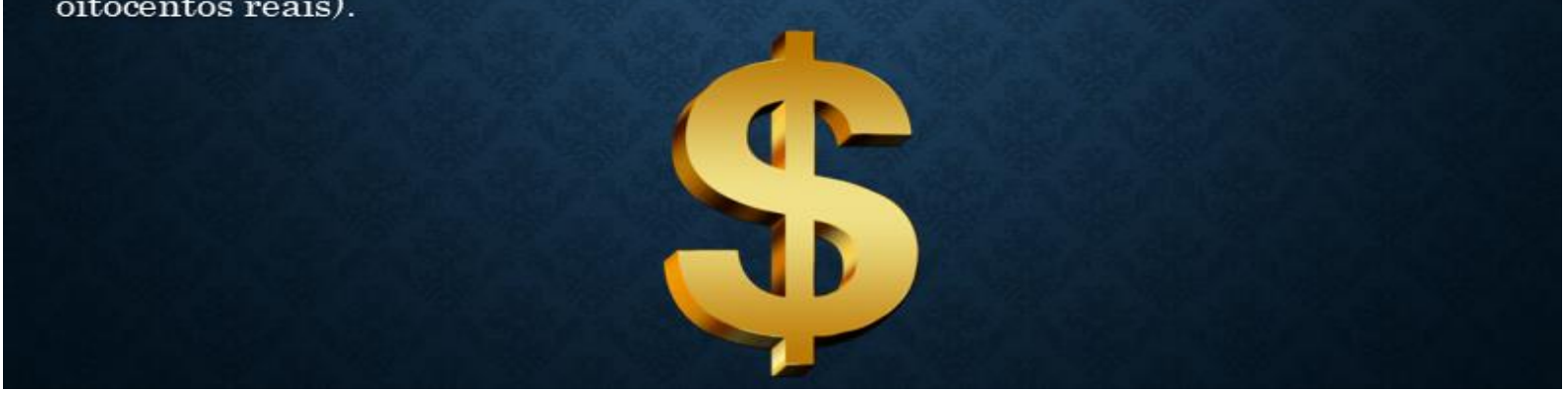

Fonte: Banco de dados dos pesquisadores

O problema seguinte seria como fazer a estimativa dos danos físicos às construções. Para isso, os alunos tiveram que buscar por mais informações. Nesse caso, não existia tabela de valores pré-fixados, pois eles dependem do mercado imobiliário de cada cidade. Como 
forma de contornar o problema, utilizaram os valores divulgados nos sites de imobiliária da região (figura 8 ).

Figura 8 - Slide da apresentação - valor médio de uma casa

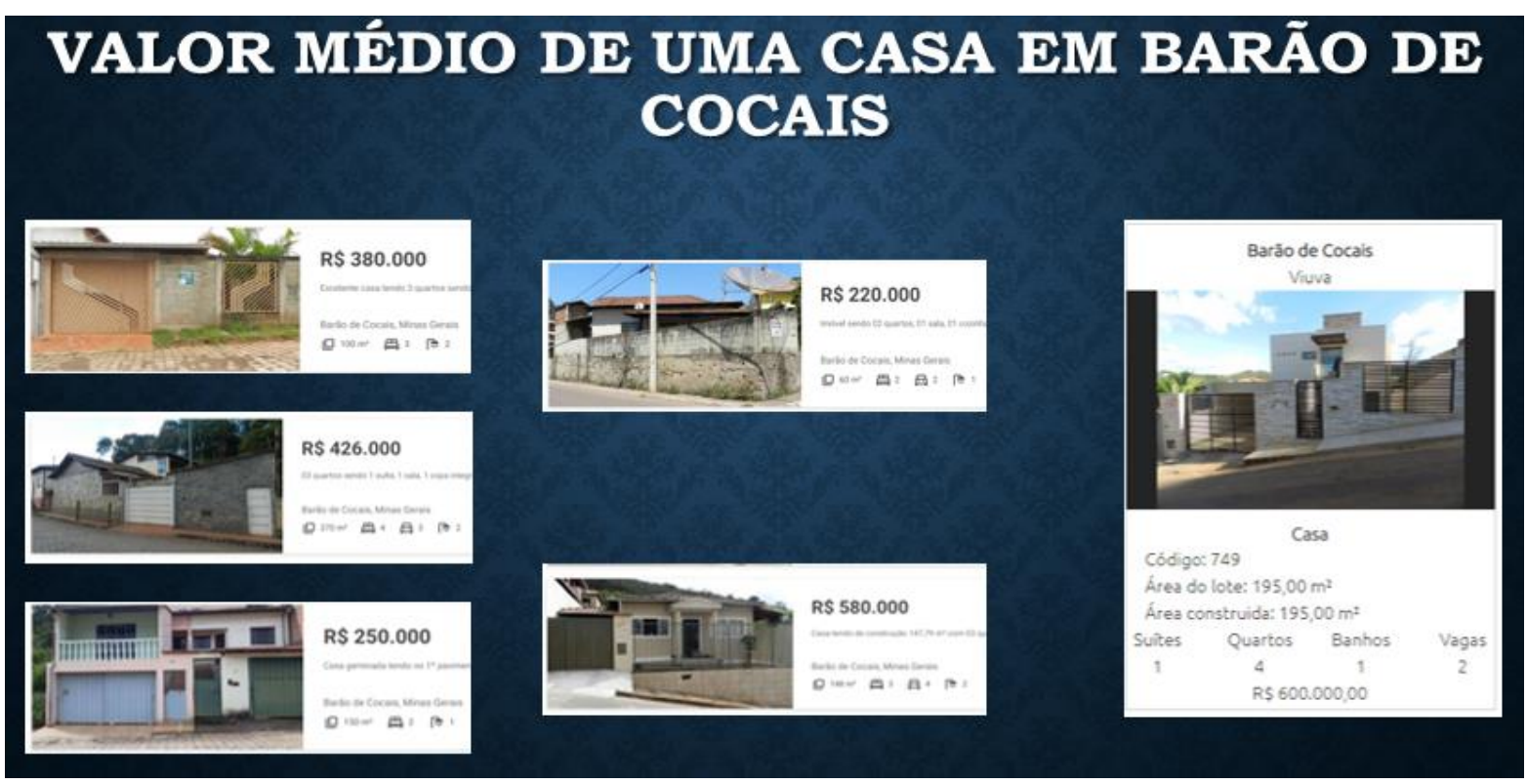

Fonte: Banco de dados dos pesquisadores

Como as informações do site não classificavam as residências em tipo A, B ou C, os alunos decidiram não classificar as residências e sim que fariam média dos valores das residências anunciadas. De posse desses dados, eles estimaram o valor de uma residência sem se preocupar com a classificação social. Em seguida, apresentaram aos colegas a estimativa do valor médio de uma residência na cidade de Barão de Cocais (figura 9).

Figura 9 - Slide da apresentação - estimativa de danos

\section{VALOR MÉDIO DE UMA CASA EM BARÃO DE COCAIS}

- Fizemos uma pesquisa em alguns sites de compra e venda e imóveis em Barão de Cocais e executamos uma média referente aos valores das casas (lembrando que nos sites haviam muitos estabelecimentos comerciais e casa repetidas, portanto, levando em consideração estas 12 residências o valor encontrado foi de $R \$ 408.790,333$ (quatrocentos e oito mil setecentos e noventa mil e trezentos e trinta e três reais).

- Levando em consideração as 3,33 mil residências afetadas o total seria, em média $\mathrm{R} \$ 1.361 .271 .810$ (um bilhão trezentos e sessenta e um milhões duzentos e setenta e um mil oitocentos e dez).

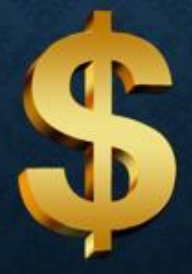

Fonte: Banco de dados dos pesquisadores 
Após obterem o valor estimado dos danos, os alunos formalizaram os procedimentos realizados e propuseram um modelo matemático que explica a situação investigada (figura 10).

Figura 10 - Slide da apresentação - Modelo Matemático

\section{MODELO MATEMÁTICO}

- Para esta análise consideramos o seguinte modelo:

Conteúdo de uma residência de classe $\mathrm{C}$ x número de residências atingidas diretamente pela lama + preço médio de uma residência x número de residências

Fonte: Banco de dados dos pesquisadores

De acordo com os alunos do grupo, esse modelo permite estimar o valor dos danos tangíveis diretos em caso de rompimento da barragem. Ao final, eles questionaram os seus colegas se eles validavam o modelo proposto e todos concordaram que sim. No entendimento da turma, o modelo proposto estava coerente com as informações apresentadas para solucionar a situação-problema colocada. Após a apresentação de todos os grupos de modelagem, ficou acordado com os alunos que o produto final do trabalho seria a confecção de um pôster a ser divulgado na escola em evento na semana de Ciência e Tecnologia.

Conforme podemos observar na atividade relatada, os dados apresentados e analisados sinalizam que os estudantes se engajaram na atividade desenvolvida desde o início de sua abordagem, pois em todos os momentos de coletas de dados tivemos respostas positivas. Salientamos que, nas atividades de modelagem desenvolvidas, as abordagens utilizadas foram pensadas e projetadas no sentido de fornecer o suporte inicial para o engajamento dos estudantes, o que permitiu ao professor organizar e reorganizar suas ações e estratégias na condução das atividades e estabelecer novas oportunidades de engajamento e de aprendizagem.

Os alunos realizaram todas as atividades de modelagem propostas comprovando, assim, o envolvimento na resolução dos problemas de modelagem. Conforme Farias e Vaz (2019), os alunos estabeleceram uma relação de engajamento com a atividade de modelagem apresentada. As informações obtidas e apresentadas pelos alunos do grupo 1, em nossa análise, mostraram que eles estavam engajados em todas as dimensões: comportamental, emocional e cognitiva, pois foi possível perceber que realizaram escolhas racionais, fundamentadas na compreensão, na modelagem, na predição e no controle de seus efeitos, diante de uma situação inédita e cheia de incertezas. Nesse sentido, eles se empenharam ao máximo, mostraram satisfação em investigar a situação-problema, demonstraram entendimento do problema investigado e apresentaram uma solução coerente para ele, movidos pelo desejo de aprender e desenvolver estratégias para promover seu entendimento do tema e sua aprendizagem em Matemática. 
O exemplo apresentado, em que os alunos aprofundaram sua investigação, discutiram o problema e buscaram uma forma de resolvê-lo, propondo uma solução coerente, mostrou que os alunos desenvolveram ações de engajamento cognitivo.

Também foi possível perceber desenvolvimento de ações de engajamento comportamental, que se relacionam à participação e ao envolvimento dos estudantes, bem como às condutas positivas empreendidas por eles. A dimensão comportamental envolve a participação e o envolvimento em uma atividade, especialmente no domínio de seu fazer (FREDRICKS et al., 2004; FARIA, 2008). O engajamento comportamental dos alunos na proposta de ensino pode ser caracterizado pela colaboração e pelo grande interesse e envolvimento nas atividades de modelagem desenvolvidas durante as duas etapas letivas investigadas. Nas atividades de ensino propostas houve engajamento na organização dos estudantes durante o processo de investigação, matematização e resolução dos problemas de Modelagem Matemática, nas discussões entre si e com os demais grupos nas apresentações. Também foi possível observar a adesão dos alunos às normas e acordos estabelecidos nos grupos de modelagem. Acordos firmados entre alunos e professores foram aceitos e cumpridos pela maior parte dos alunos. Por exemplo, quanto às normas de uso de informações retiradas da internet, de não utilizar informações falsas ou que não viessem de fontes confiáveis. Tais ações também comprovam engajamento comportamental.

Outras ações de engajamento comportamental foram observadas nas transcrições das falas dos alunos durante o desenvolvimento das atividades de modelagem, em ações relacionadas ao respeito às ideias, opiniões e sugestões dos colegas na busca por solucionar as situações investigadas. Essas ações fazem parte do processo em atividades de modelagem, pois os alunos durante as explorações preliminares sobre o assunto precisam formular questões, levantar hipóteses e expor suas ideias e sugestões, opinando sobre o problema investigado (JACOBINI; WODEWOTZKI, 2006).

É importante salientar que alguns autores acreditam que as atividades de Modelagem Matemática, pelos seus procedimentos investigativos, contribuem para ações de engajamento, em todas as suas dimensões. Pois, conforme afirmam Almeida, Silva e Vertuan (2012) as características das atividades de modelagem, em geral, desafiam os estudantes levando-os a enfrentar algo, que de algum modo pode ser novo, dando a eles a oportunidade de se familiarizar com mecanismos de ação e reflexão. É importante destacar também que em algumas ações de motivação, propostas pelos professores, "os alunos tendem a fugir dos desafios, a perder iniciativa e a se contentar com meras reproduções dos conteúdos ou simplesmente chegar ao término da atividade, sem preocupação com a qualidade" (BZUNECK; MEGLIATO; RUFINI, 2013, p.153). Nesta pesquisa, ocorreram situações semelhantes.

As ações de motivação percebidas mostraram que, na prática, como era esperado pelos estudos feitos, os alunos realizaram com dedicação as atividades de modelagem, em primeiro lugar, por se identificar com as atividades propostas, por gostarem de realizar atividades investigativas e de aplicação da matemática e, porque se preocupam com o aprendizado da Matemática, obtendo bons resultados e aprovação na disciplina.

Em relação às outras atividades de modelagem realizadas, também entendemos que houve contribuições para o desenvolvimento de ações de motivação e engajamento. Sendo importante destacar que os dados coletados mostram que alguns alunos tiveram dificuldades de se engajar. Alguns na dimensão comportamental, outros na dimensão emocional e outros na cognitiva. Conforme os pesquisadores ponderam (FREDRICKS et al., 2004; FARIA, 2008, 
FARIAS; VAZ, 2019), isso se deu em função das características do engajamento individual de cada aluno e da proposta de ensino.

Concluímos que a utilização das atividades de Modelagem Matemática contribuiu para o desenvolvimento de ações de motivação e engajamento dos alunos na disciplina de Matemática no Ensino Médio. Os dados coletados mostraram indícios de indicadores de motivação e engajamento durante as abordagens realizadas na proposta de ensino investigada. No entanto, conforme ponderações de Farias e Vaz (2019),

\begin{abstract}
se o professor sabe que ter os estudantes envolvidos na tarefa é condição necessária, mas não suficiente, para considerar que eles estão engajados, ele sabe também que precisa dar maior atenção ao tipo de envolvimento, à natureza das ações, ao conteúdo das falas e a outros aspectos da atuação dos estudantes. Se o objetivo do ensino é a aprendizagem e aprendizagem é uma função do engajamento cognitivo, não basta fazer os estudantes se engajarem. (FARIAS; VAZ, 2019, p. 22).
\end{abstract}

Segundo os autores, é preciso trabalhar para que os estudantes se envolvam, estejam motivados, engajem nas atividades em todas as dimensões e essa proposta de ensino trouxe contribuições nesse sentido.

\title{
7 Conclusão
}

Neste artigo, analisamos os dados e discutimos os resultados obtidos no desenvolvimento de atividades de Modelagem Matemática como estratégias para desenvolver e promover ações de motivação e engajamento em Matemática no Ensino Médio. Pela análise e discussão apresentadas, analisamos que a proposta de ensino pode oferecer contribuições para o desenvolvimento de ações de motivação e engajamento dos alunos na disciplina.

$\mathrm{Na}$ proposta de ensino, as atividades de Modelagem Matemática oportunizaram também a abordagem de conceitos e conteúdo, o desenvolvimento de competências, habilidades, o aprimoramento e compreensão de argumentos matemáticos e a valorização da própria Matemática. Também podemos inferir que o uso da Modelagem Matemática possibilitou uma aprendizagem contextualizada da matemática e desenvolver competências críticas e reflexivas sobre situações relacionadas à sociedade em que vive o aluno, bem como sobre a aplicação da Matemática fora do ambiente escolar.

Conforme apresentamos, ficou evidenciado que a proposta de ensino possibilitou a construção de um ambiente de aprendizagem que permitiu aos alunos investigar situações e problemas do seu contexto social, e neste ambiente, a problematização e investigação foram sustentadas pela motivação e engajamento dos alunos em buscar soluções, compreender os conteúdos matemáticos e mobilizar conhecimentos prévios que emergiram dos processos de investigação e de interação entre os alunos e professores.

Portanto, pelos resultados apresentados, concluímos que o objetivo principal da investigação foi atingido, pois implementamos, analisamos e avaliamos uma proposta de ensino e identificamos e caracterizamos os contributos da Modelagem Matemática para os processos de ensino e aprendizagem da Matemática no Ensino Médio. 


\section{Referências}

ALI, M.; HASSAN, N. Defining concepts of student engagement and factors contributing to their engagement in schools. Creative Education, v. 9, n. 14, p. 2161-2170, 2018.

ALMEIDA, L. M. W.; DIAS, M. R. Um Estudo sobre o Uso da modelagem matemática como Estratégia de Ensino e Aprendizagem. Bolema, n. 22, p. 19-35, Rio Claro, 2004.

ALMEIDA, L. M. W.; SILVA, K. A. P.; VERTUAN, R. E. Modelagem Matemática na Educação Básica. São Paulo: Contexto, 2012.

BARBOSA, J. Modelagem matemática: Concepções e Experiências de Futuros Professores. $253 \mathrm{f}$. Tese (Doutorado). Instituto de Geociências e Ciências Exatas, Universidade Estadual Paulista, Rio Claro, 2001.

BLUM, W.; FERRI, R. B. Mathematical Modelling: can it be taught and learnt? Journal of Mathematical Modelling and Aplication, Blumenau, v. 1, n. 12, p. 45-58, 2009.

BLUM, W. Quality teaching of mathematical modelling: What do we know, what can we do?. In: THE PROCEEDINGS OF THE 12TH INTERNATIONAL CONGRESS ON MATHEMATICAL EDUCATION.

Proceedings... Springer, Cham, p. 73-96, 2015.

BRASIL. Base Nacional Comum Curricular (BNCC). Educação é a Base. Brasília, MEC/CONSED/UNDIME, 2017. Disponível em:

http://basenacionalcomum.mec.gov.br/images/BNCC publicacao.pdf. Acesso em: 18 abr. 2018.

BZUNECK, J. A.; MEGLIATO, J. G. P.; RUFINI, S. E. Engajamento de adolescentes nas tarefas escolares de casa: uma abordagem centrada na pessoa. Psicologia Escolar e Educacional, v. 17, n. 1, p. 151161, 2013.

CAMARGO, C. A. C. M.; CAMARGO, M. A. F.; SOUZA, V. O. A importância da motivação no processo ensino-aprendizagem. Revista Thema, v. 16, n. 3, p. 598-606, 2019.

FARIA, A. F. Engajamento de estudantes em atividade de investigação. 2008. 119p. Dissertação (Mestrado) - Faculdade de Educação, Universidade Federal de Minas Gerais, Belo Horizonte, 2008.

FARIA, A. F.; DE MOURA VAZ, A. Engajamento de Estudantes em Investigação Escolar sobre Circuitos Elétricos Simples. Ensaio Pesquisa em Educação em Ciências, v. 21, 2019.

FERREIRA, N. S. Modelagem Matemática e Tecnologias de Informação e Comunicação como ambiente para abordagem do conceito de Função segundo a Educação Matemática Crítica. 243 f. Dissertação (Mestrado) - Universidade Federal de Ouro Preto, Ouro Preto, 2013.

FREDRICKS, J. A.; BLUMENFELD, P. C.; PARIS, A. H. School engagement: potential of the concept, state of the evidence. Review of Educational Research, n.74, v.1, p. 59-109, 2004.

JACOBINI, O. R.; WODEWOTZKI, M. L. L. Uma reflexão sobre a Modelagem Matemática no contexto da Educação Matemática Crítica, Bolema, n.25, p.71-88, 2006. 
KAISER, G. Mathematical modelling and applications in education. Encyclopedia of mathematics education, p. 396-404, 2014.

MALHEIROS, A. P. S. Pesquisas em Modelagem Matemática e diferentes tendências em Educação e em Educação Matemática. Bolema: Boletim de Educação Matemática, v. 26, n. 43, p. 861-882, 2012.

OLIVEIRA, C. B. E.; ALVES, P. B. Ensino fundamental: papel do professor, motivação e estimulação no contexto escolar. Paidéia (Ribeirão Preto) [online], Ribeirão Preto, v.15, n.31, p.227-238, ago. 2005.

PLOMP, T.; NIEVEEN, N. Educational design research part A: An introduction. Enchede, The Netherlands: SLO, 2013.

RAMOS, P. Ambiente virtual vivências: análise do processo de desenvolvimento na perspectiva da pesquisa baseada em design. $238 \mathrm{f}$. Tese (Doutorado), UFRJ/NUTES, Rio de Janeiro. 2010.

RAMOS, R.C.S.S.; TRISCH, E.; SALVI, R. F. Modelagem Matemática como possibilidade de motivação do aluno - o caso da feira de matemática. in: II CNEM - CONGRESSO NACIONAL DE EDUCAÇÃO MATEMÁTICA, IX EREM - ENCONTRO NACIONAL DE EDUCAÇÃO MATEMÁTICA, v. 2, n. 23, 2011, ljuí, RS. Anais... UNIJUÍ, ljuí, p. 1-13, 2011.

RODRIGUES, M. A. S.; Healy, L. MusiCALcolorida: formas musicais e coloridas para representar e explorar números. 2008. Disponível em:

http://www.matematicainclusiva.net.br/Executaveis/MusiCALcolorida\%20\%20formas\%20musicais\% 20e\%20coloridas\%20para\%20representar\%20e\%20explorar\%20numeros, acesso em 20/04/2019.

SILVA, C. Aprendizagem Significativa em atividades de Modelagem Matemática, $145 \mathrm{f}$. Tese (Doutorado em Ensino de Ciências e Educação Matemática) Instituição de Ensino) - Universidade Estadual de Londrina, Londrina, 2018.

SKINNER, E. A.; FURRER, C.; MARCHAND, G.; KINDERMANN, T. Engagement and disaffection in the classroom: Part of a larger motivational Dynamic? Journal of Educational Psychology, v. 100, n. 4, p. 765-781. 2008.

VERTUAN, R. E. Um olhar sobre a modelagem Matemática à luz da teoria dos registros de representação semiótica.141 f. Dissertação (Mestrado). Universidade Estadual de Londrina, Ensino de Ciências e Educação Matemática, Londrina. 2007.

VIDIGAL, C. L. Desenvolvendo criticidade e criatividade com estudantes de geografia por meio de modelagem. 148 f. Dissertação (Mestrado Profissional em Educação Matemática) - Universidade Federal de Ouro Preto, Ouro Preto, 2013. 